\title{
Differential effects of the changes of LDL cholesterol and systolic blood pressure on the risk of carotid artery atherosclerosis
}

\author{
Kuo-Liong Chien ${ }^{1,2}$, Yu-Kang Tư ${ }^{3}$ Hsiu-Ching Hsu², Ta-Chen Su², Hung-Ju Lin², Ming-Fong Chen ${ }^{2}$ and
} Yuan-Teh Lee L, $^{2 *}$

\begin{abstract}
Background: The effects of baseline and changes in blood pressure and low density lipoprotein (LDL) cholesterol on the carotid intima media thickness (IMT) have not been well documented.

Methods: A total of 2572 adults (mean age 53.8 years, 54.6\% women) in a Taiwanese community undertook three blood pressure and LDL cholesterol examinations over 6 years. Latent growth curve modeling was used to investigate the effects of baseline and change in blood pressure and LDL cholesterol on IMT.

Results: Greater baseline LDL and blood pressure were associated with an increase in IMT $(0.005 \pm 0.002 \mathrm{~mm}$ per $1 \mathrm{mg} / \mathrm{dL}[p=0.006]$ and $0.041 \pm 0.004 \mathrm{~mm} \mathrm{mmHg}[p<0.0001]$, respectively. Change in blood pressure was associated with a significant increase in IMT $(0.047 \pm 0.016, P=0.004)$, whilst the association between change in LDL and change in IMT was not statistically significant $(0.008 \pm 0.006, P=0.20)$.
\end{abstract}

Conclusions: Carotid IMT was associated with baseline blood pressure and LDL cholesterol, yet only changes of blood pressure, not LDL cholesterol, were related to carotid IMT during the 6-year observation.

Keywords: Latent growth curve modeling, Carotid intima media thickness, Blood pressure, LDL cholesterol

\section{Background}

It has been suggested that carotid intima media thickness (IMT) is associated with metabolic syndrome components. One cross-sectional study on 2268 Americans showed that the average increase in IMT was $0.52 \mathrm{~mm}$ in people with no metabolic syndrome and $0.69 \mathrm{~mm}$ in people with 4 metabolic syndrome components [1]. However, the cross-sectional study design and the analysis of non-specific components provides limited evidence for a causal interpretation of these associations [1]. A randomized controlled trial which recruited more than 19000 adults in Europe showed that a reduction in both lipids and blood pressure decreased the risk of cardiovascular events [2], indicating that blood pressure

\footnotetext{
* Correspondence: ytlee@ntu.edu.tw

${ }^{2}$ Department of Internal Medicine, National Taiwan University Hospital, Taipei, Taiwan

${ }^{4}$ China Medical University Hospital, Taichung, Taiwan

Full list of author information is available at the end of the article
}

and lipids may play an important role in the risk of atherosclerosis.

IMT of the common carotid artery are considered useful indicators of carotid atherosclerosis [3-5]. Al-Shali and colleagues [6] found that age and hypertension were associated with carotid IMT, whereas total cholesterol, current smoking, diabetes, and gender were not. It is noted that most studies have not distinguished differences in blood pressure and lipid profiles [5,7]. Evidence on the cumulative effects of blood pressure and cholesterol is insufficient. Some studies have shown that carotid plaque score is associated with an increased risk of cardiovascular disease [7-11], but results from clinical trials on the relationship between the reduction in blood pressure and cholesterol and change in IMT are inconsistent [12-14]. Previous controlled trials showed that except diuretics, blood pressure lowering medication and statin decreased IMT modestly $[15,16]$, whilst the associations of blood pressure and LDL cholesterol with carotid IMT remain unclear. It would therefore be useful

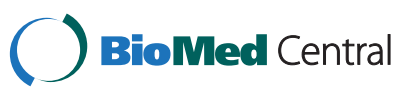


to look into the effects of changes in repeated blood pressure and cholesterol measurements on IMT in longitudinal cohorts. The aim of this study is to use repeated measurements of blood pressure and LDL cholesterol levels over 6 years to investigate the effects of changes in blood pressure and cholesterol on carotid IMT among Taiwanese adults in a community cohort.

\section{Methods}

\section{Study design and participants}

Details of this cohort have been reported elsewhere [1719]. Briefly, the Chin-Shan Community Cardiovascular Cohort Study (CCCC) started in 1990 by recruiting 1703 men and 1899 women of Chinese ethnicity aged 35 years old and above from the Chin-Shan township, $30 \mathrm{~km}$ north of metropolitan Taipei, Taiwan. Information about the lifestyle and medical conditions were collected with questionnaires from in-person interviews every 2 years for the initial 6 years up to 1994-1995. The validity and reproducibility of these measurements have been published previously [19]. A total of 2244 participants had complete carotid ultrasonography measurements in 1994-1995 after incomplete data of blood pressure, lipid $(\mathrm{n}=328)$, and incomplete carotid ultrasonography $(\mathrm{n}=1030)$ were excluded (Additional file 1: Table S1). The National Taiwan University Hospital Institutional Review Board approved the study protocol, and the informed consent for participation in the study was obtained from each participant.

\section{Clinical measurements and biochemical markers}

Body mass index was calculated as weight (in kilograms) over height (in meters) squared. Blood pressure was measured twice on the right arm supported and positioned at the level of the heart with a mercury sphygmomanometer, after participants were seated comfortably for ten minutes. All participants were asked to refrain from smoking cigarettes for at least 30 minutes and from drinks with caffeine before examination.

Hypertension was defined according to the criteria established by the Seventh Joint National Committee [20]: systolic blood pressure more than or equal to $140 \mathrm{mmHg}$ or diastolic blood pressure more than or equal to 90 mmHg; or a history of taking hypertension medications.

Repeated measurements of blood pressure and lipid profiles were collected biannually from 1990, and the procedures for taking blood samples have been reported elsewhere [21,22]. Briefly, all venous blood samples drawn after a 12-hour overnight fast were immediately refrigerated and transported within 6 hours to the $\mathrm{Na}$ tional Taiwan University Hospital. Serum samples were then stored at $-70^{\circ} \mathrm{C}$ before biochemical analysis of total cholesterol, triglycerides, and high density lipoprotein (HDL) cholesterol. Standard enzymatic tests for serum cholesterol and triglycerides were used (Merck 14354 and 14366, Germany, respectively). HDL levels were measured in supernatants after the precipitation of specimens with a magnesium chloride phosphotungstate reagent (Merck 14993). LDL cholesterol concentrations were calculated as total cholesterol minus cholesterol in the supernatant by a precipitation method (Merck 14992) [23].

\section{Ultrasound imaging on carotid artery measurements}

The procedures for ultrasound sonography of carotid arteries have been reported elsewhere $[17,24]$, and the recommendation from the expert recommendation was strictly followed [25]. In brief, IMT were measured by using a Hewlett-Packard SONO 1500 ultrasound system, equipped with a $7.5 \mathrm{MHz}$ real-time B-mode scanner. Patients were asked to lie supinely with the neck extended in a slightly lateral rotation. We then scanned the carotid artery and identified the lumen of the carotid artery beneath the surface of the neck. IMT was defined as the distance between the front edge of the first echogenic line (lumen-intima interface) and the front edge of the second line (media-adventitia interface) in the far wall of the vessel. The same procedure was undertaken on the other side of the neck. The measurement of IMT was made on the ECG-gated R-wave (diastole) phase using a semiautomated technique. Two measures were made on each side. The measurement of IMT over the distal $1 \mathrm{~cm}$ of the common carotid artery was noted [24]. The maximum IMT was defined by averaging maximum measurements on both sides [26]. Participants' medical status was unknown to cardiologists who carried out the examinations. The inter-examiner correlation coefficients ranged from 0.86 to 0.93 , and the intra-examiner correlation coefficients ranged from 0.70 to 0.87 for both sides of common carotid artery IMT measurements. We excluded participants with IMT more than $1.5 \mathrm{~mm}$ and those with significant plaque formation.

\section{Statistical analysis}

Continuous variables are presented as mean and standard deviation, and categorical variables in contingency tables. We used a linear regression model to test the associations of repeated systolic blood pressure and LDL with the carotid IMT. We used the diagnostic tools for collinearity, namely the tolerance and variance inflation factors, to evaluate the multicollinearity problem in our model [27].

Latent growth curve modeling, a special application of structural equation modeling (SEM), was then used to analyze the associations between changes in LDL cholesterol and systolic blood pressure (SBP) over the 6-year period and final IMT. Separate non-linear latent growth curve model analyses for LDL cholesterol and carotid 
IMT and for systolic blood pressure were undertaken [28]. Figure 1 shows the path diagram for the bivariate latent growth curve model. Briefly, one part of latent growth curve models used two latent variables to estimate baseline SBP and LDL and their changes over 6 years (F1 \& F2 for SBP and F3 \& F4 for LDL in Figure $1)$. For example, in the SBP model, the three observed SBP can be expressed as three linear regression models of F1 and F2, and the coefficients are regression weights, also known as factor loadings, for F1 and F2. When the first coefficient fixed to equal 0 and third coefficient

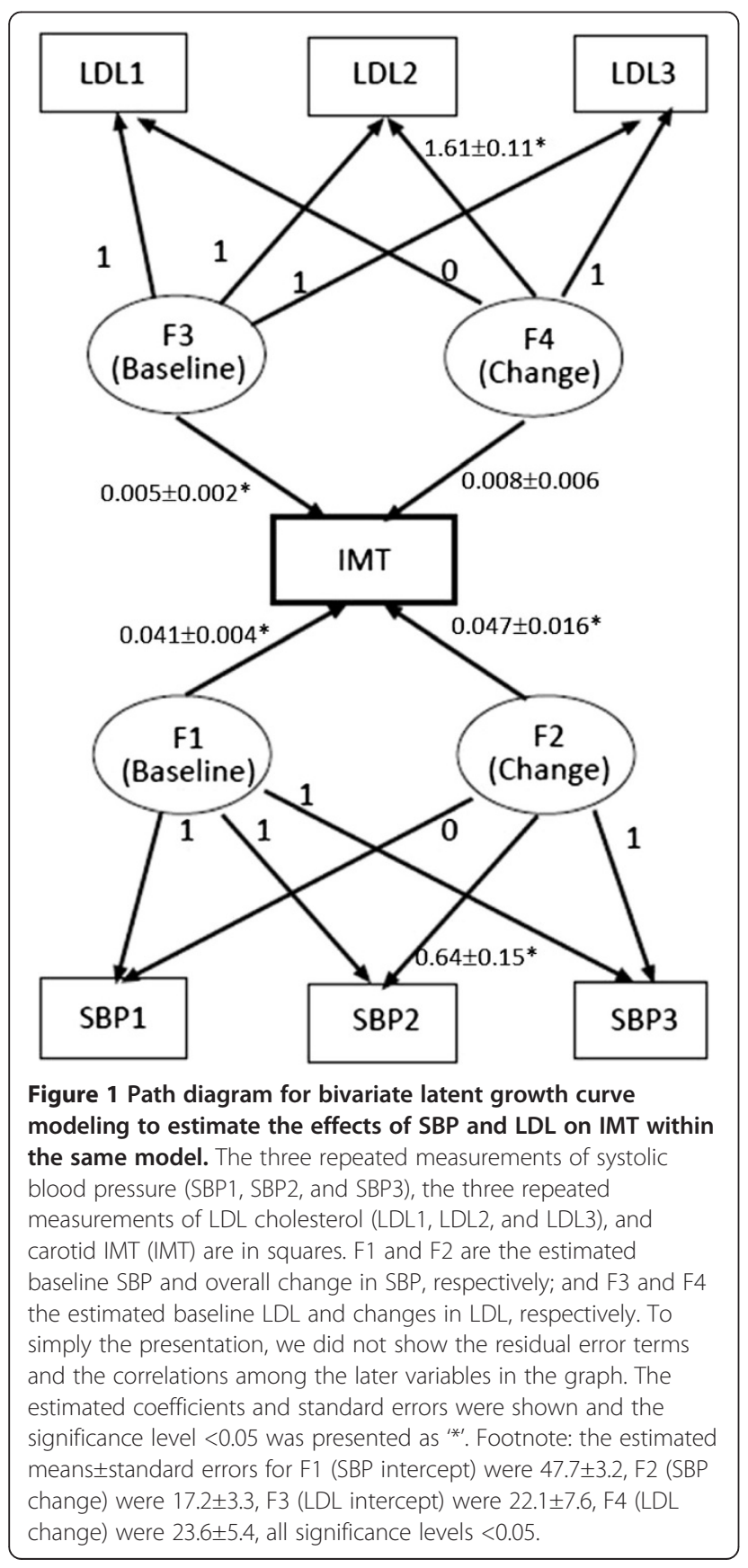

fixed to unity, F1 becomes the estimated baseline SBP, and F2 becomes the overall change in SBP. If velocity of change in SBP is constant, we can fit a linear growth curve model by fixing the second coefficient to equal 0.5 (because the three SBP were measured every 2 years). In other words, latent growth curve modeling aims to estimate baseline values and changes from baseline using the observed repeated measurements. One advantage of this approach is to reduce the number of variables in the model and to overcome the problem with collinearity. From a statistical point of view, latent growth curve modeling is equivalent to multilevel modeling for longitudinal data, and a non-technical introduction to latent growth curve modeling can be found in our previous publication [29]. We can also allow the factor loading for intermediate measurements to be freely estimated; if the changes in LDL or systolic blood pressure were linear, the factor loading for the intermediate measurement would be close to 0.5 . The advantages of this approach are that a nonlinear change pattern can be estimated without using polynomial functions, and the means or intercept for the latent variables for changes (i.e. F2) can be directly interpreted as the total changes from baseline over the observation period. Age at baseline, sex, and body mass index were adjusted as confounders.

Next, a bivariate latent growth curve model was then constructed in which the IMT was regressed on the baseline and changes of both LDL cholesterol and systolic blood pressure. Covariates, including age, gender, and baseline body mass index were also included in the final model. IMT values were multiplied by 100 to prevent rounding errors in the computation. Several statistics were evaluated for the overall model fit: (1) a small chi-square value for model fit relative to the model degrees of freedom with a $P$ value greater than 0.05 indicated that the proposed model fitted the data relatively well; (2) a comparative fit index (CFI) greater than 0.95 indicated a good model; (3) a Root Mean Square Error of Approximation (RMSEA) value less than 0.05 was considered as a good model; and (4) a Standardized Root Mean Square Residual (SRMR) less than 0.1 indicated a good model fit [30]. All statistical analyses were performed with the statistical software packages SAS version 9.1.3 and Mplus version 5 [31].

\section{Results}

A total of 2244 adults (mean age of 54.3 years; 1238 women) were recruited into this study. Table 1 provides a summary of three repeated measurements of blood pressure, LDL cholesterol and carotid IMT. LDL cholesterol decreased in later examinations, yet non-HDL cholesterol and systolic blood pressure values increased progressively. The prevalence rates of elevated LDL level ( $>=220 \mathrm{mg} / \mathrm{dL}$ ) in the study participants were $2-4 \%$ and 
Table 1 Basic characteristics of three repeated measurements of blood pressure and lipid profiles, and carotid intima media thickness values in the study participants who provided completed carotid data $(n=2244)$

\begin{tabular}{lcc}
\hline & N & \% \\
\hline Gender & 1238 & \\
\hline Women & 1006 & 55.2 \\
\hline Men & 751 & 44.8 \\
\hline Current smoking & Mean & 33.5 \\
\hline & 54.3 & SD \\
\hline Age, years & 23.7 & 11.7 \\
\hline Body mass index, $\mathrm{kg} / \mathrm{m}^{2}$ & 139.8 & 3.4 \\
\hline 1st LDL cholesterol, $\mathrm{mg} / \mathrm{dL}$ & 123.0 & 43.8 \\
\hline 2nd LDL cholesterol, $\mathrm{mg} / \mathrm{dL}$ & 129.9 & 43.5 \\
\hline 3rd LDL cholesterol, $\mathrm{mg} / \mathrm{dL}$ & 125.0 & 39.4 \\
\hline 1st Systolic BP, mmHg & 125.6 & 20.2 \\
\hline 2nd Systolic BP, mmHg & 126.0 & 19.9 \\
\hline 3rd Systolic BP, mmHg & 47.0 & 19.4 \\
\hline 1st HDL cholesterol, mg/dL & 109.8 & 12.2 \\
\hline 1st fasting glucose, mg/dL & 0.74 & 30.6 \\
\hline Carotid intima media thickness, mm & 0.24
\end{tabular}

Abbreviations: $L D L$, low density lipoprotein; $H D L$, high density lipoprotein; $B P$, blood pressure.

the rates of high blood pressure $(>=140 \mathrm{mmHg}$ ) were $20-24 \%$.

Using a multiple linear regression model (Table 2), we found that age, gender and the first and second systolic pressure was modestly associated with carotid IMT $(P<0.05)$. However, due to the problem with high

Table 2 The estimated coefficients, standard errors, and significance levels of repeated measurements of systolic blood pressure and LDL-C levels for the carotid IMT magnitude using traditional multiple linear regression model in the study participants

\begin{tabular}{|c|c|c|c|c|}
\hline Covariates & Unit & Estimate & Standard error & $P$ \\
\hline Intercept & & -1.76 & 0.58 & 0.003 \\
\hline Age & $+1 \mathrm{yr}$ & 0.086 & 0.004 & $<.0001$ \\
\hline Gender & Men vs. women & 0.56 & 0.13 & $<.0001$ \\
\hline Body mass index & $+1 \mathrm{~kg} / \mathrm{m}^{2}$ & -0.018 & 0.015 & 0.23 \\
\hline Smoking status & Yes vs. no & 0.316 & 0.135 & 0.019 \\
\hline 1st HDL cholesterol & $+1 \mathrm{mg} / \mathrm{dL}$ & -0.004 & 0.004 & 0.28 \\
\hline 1st fasting glucose & $+1 \mathrm{mg} / \mathrm{dL}$ & 0.002 & 0.002 & 0.18 \\
\hline 1st Systolic BP & $+1 \mathrm{mmHg}$ & 0.009 & 0.003 & 0.007 \\
\hline 2nd Systolic BP & $+1 \mathrm{mmHg}$ & 0.017 & 0.003 & $<.0001$ \\
\hline 3rd Systolic BP & $+1 \mathrm{mmHg}$ & 0.005 & 0.003 & 0.16 \\
\hline 1st LDL cholesterol & $+1 \mathrm{mg} / \mathrm{dL}$ & 0.001 & 0.001 & 0.39 \\
\hline 2nd LDL cholesterol & $+1 \mathrm{mg} / \mathrm{dL}$ & 0.001 & 0.001 & 0.37 \\
\hline 3rd LDL cholesterol & $+1 \mathrm{mg} / \mathrm{dL}$ & 0.003 & 0.002 & 0.07 \\
\hline
\end{tabular}

Abbreviations: $B P$ : blood pressure, $L D L$ : low density lipoprotein. correlations amongst the explanatory variables, the three LDL cholesterol and the third systolic blood values had non-significant associations with the carotid IMT. The regression diagnostic tests, including variance inflation factors and collinearity diagnostic statistics, showed substantial collinearity among the variables.

Results from the bivariate latent growth curve model are shown in Figure 1. The estimated factor loading for the intermediate measurement was 1.61 for LDL cholesterol and 0.62 for systolic blood pressure change, indicating non-linear increases in repeated LDL cholesterol and systolic blood pressure during the observation period. In addition, one unit increase of baseline LDL ( $\mathrm{mg} / \mathrm{dL}$ ) and blood pressure $(\mathrm{mmHg})$ was associated with a $0.005 \mathrm{~mm}$ (95\% confidence interval [CI]: 0.001 to 0.009 ) and $0.041 \mathrm{~mm}$ (95\% CI: 0.033 to 0.049 ) increase in carotid IMT, respectively. An increase in blood pressure was significantly associated with a modest increase in IMT $(0.047$ per $1 \mathrm{mmHg}$; 95\% CI: 0.015 to $0.079, P=0.004)$. However, the positive association between the increase in LDL and carotid IMT was not statistically significant (0.008 per $1 \mathrm{mmHg}$; 95\% CI: -0.004 to $0.020, P=0.20)$. The final model fit the data well; the chi-square $(\mathrm{DF}=15)$ value was 21.2 with the $\mathrm{p}$-value as 0.13 , indicating the relations amongst the variables in the model were consistent with (non-sig different from) the observed data.

\section{Discussion}

In this Taiwanese cohort, we found associations of carotid IMT with blood pressure and LDL cholesterol. When their effects were taken into account simultaneously, the positive association between the increase in LDL cholesterol and IMT became attenuated and nonsignificant. This indicates that change in systolic blood pressure may be a better predictor or a stronger risk factor for IMT.

The effects of blood pressure and lipids on carotid IMT have been reported in previous studies $[1,32]$. In one study based on 2268 adults who undertook health examinations, increased numbers of metabolic risk factors were associated with an increased IMT in different ethnic groups [1]. Another study based on 1809 young Finnish adults also showed that metabolic components were significantly associated with carotid IMT, and the progress of IMT among these young adults was related to obesity, LDL and insulin resistance [32]. Another small study in Italy (240 healthy adults) from health checkups also showed an additive synergistic effect of metabolic components for IMT [33]. Exploratory factor analysis was used to extract three factors; obesity/dyslipidemia, hypertension, and hyperglycemia [33]. However, the specific effects of the components were unclear in the factor analysis strategy. In addition, these studies were cross-sectional in design, without considering the cumulative effects of both blood 
pressure and lipids on carotid atherosclerosis. Our findings from the multiple linear regression model showed similar findings to those in the study of Al-Shali and colleagues [6]. In this study, we used latent growth curve modeling to investigate the associations of both baseline and changes in blood pressure and lipids on carotid IMT. Change in blood pressure seems to have a stronger effect on IMT than change in LDL cholesterol, suggesting the effects of lipid-lowering treatment on carotid IMT regression might be small [34]. This is consistent with the findings from clinical trials on lipid-lowering therapies in which medications for reducing LDL had inconsistent effects on IMT, as shown by numerous statin studies including METEOR (rosuvastatin) [35], ACAPS (lovastatin) [36], KAPS (pravastatin) [37], PLAC-II (pravastatin) [38], BCAPS (fluvastatin) [39], FAST (pravastatin) [40], and REGRESS (pravastatin) [41]. The stronger association between changes in blood pressure and IMT may be because the hemodynamic change of blood pressure had a stronger impact on carotid intima media thickness, while injuries caused by LDL changes affected the carotid IMT slowly and did not manifest during the study period. Consequently, the change in IMT caused by carotid blood flow may be an important indicator for endothelial function. Evidence from antihypertensive clinical trials showed that change of BP was related to the severity of carotid IMT regression, and results from our observational study seem to support the same hypothesis that carotid IMT is primarily a mechanism of medial hypertrophy.

Evidence from randomized controlled trial data also showed differential effects of blood pressure and cholesterol lowering on carotid atherosclerosis. Among 508 combined hypertensive and hypercholesterolemic patients under a randomized control trial for 2.6 years, the progression of the carotid IMT were not significant for patients treated with fosinopril $(-0.002 \pm 0.004 \mathrm{~mm})$ or those with fosinipril and prastatin $(-0.002 \pm 0.004 \mathrm{~mm})$ [15]. Adding LDL cholesterol lowering drugs did not seem to affect the change of IMT under the blood pressure lowering effects, which was also consistent with our findings. Antihypertensive drugs were related to the carotid IMT progression or regression, and the mechanism is complex. For example, the net arterial volume expansion developed as a decrease in carotid IMT after antihypertensive medication. Therefore, further investigation on different mechanisms of carotid IMT progress by blood pressure lowering drugs was warranted.

Latent growth curve modeling is a new tool to biomedical and epidemiological research, while it has been widely used in the social sciences. Using software packages for structural equation modeling, latent growth curve modeling provides a flexible statistical framework for the analysis of repeated measures in clinical practice to investigate the baseline and changes of exposure to outcomes [29,42]. The main advantage of using latent growth curve modeling instead of traditional approaches is that repeated measurements of multiple variables (e.g. LDL and systolic blood pressure in this study) can be incorporated into one single model, and their association with a distant outcome (e.g. IMT) can then be tested. This method has been successfully applied in psychology and sociology [43], and could be a very useful tool for longitudinal data analysis in medical research $[44,45]$. In this study, we used latent growth curve modeling to estimate the effects of baseline values and changes from baseline on the carotid IMT. The clinical implication of our findings was two fold: firstly, baseline blood pressure and lipids are risk factors for carotid atherosclerosis severity; and secondly, keeping optimal blood pressure levels may be helpful for reducing carotid IMT.

Several limitations of our study should be mentioned. First, IMT, rather than plaque status, was the outcome for our investigation. Previous studies have shown that the numbers of plaque were related to cardiovascular complications [46] and events [47]. Second, we did not include the medications for lipid and blood pressure in our analysis because that information was not available. Third, we did not measure mean carotid IMT in the study participants, because our protocol was designed to measure maximal carotid IMT values [24]. Finally, carotid IMT magnitude was measured once and we did not estimate the progress of the IMT.

\section{Conclusions}

In conclusion, our study found that carotid IMT was associated with baseline blood pressure and LDL cholesterol measurements, but only changes in blood pressure, not LDL cholesterol, were related to carotid IMT in this Taiwanese cohort.

\section{Additional file}

Additional file 1: Table S1: Scheme for the recruitment of the study participants in this study.

\section{Competing interests}

All authors declare no competing interests for preparing the draft.

\section{Authors' contributions}

KLC carried out the design and data collection and drafted the manuscript. YKT carried out statistical analysis and revised the draft. $\mathrm{HCH}$ participated in laboratory data quality control and biochemical analysis. TCS participated in collecting data and maintaining the study. HJL participated in collecting data. MFC and YTL conceived of the study, and participated in its design and coordination and helped to draft the manuscript. All authors read and approved the final manuscript.

\section{Acknowledgements}

This work was partly funded by the National Science Council, Executive Yuan, Taiwan (grant NSC 100-2314-B-002 -113 -MY3, and NSC 100-2923-I002-001-MY2). The authors would like to thanks participants in the Chin-Shan 
community for taking part in this study. The authors would also like to thank Mr Andrew Woolston for editing the English in the manuscript.

\section{Author details}

'Institute of Epidemiology and Preventive Medicine, College of Public Health, National Taiwan University, Taipei, Taiwan. ${ }^{2}$ Department of Internal Medicine, National Taiwan University Hospital, Taipei, Taiwan. ${ }^{3}$ Division of Biostatistics, Leeds Institute of Genetics, Health \& Therapeutics, University of Leeds, Leeds, UK. ${ }^{4}$ China Medical University Hospital, Taichung, Taiwan.

Received: 18 October 2011 Accepted: 9 August 2012

Published: 17 August 2012

\section{References}

1. Adolphe A, Cook LS, Huang X: A cross-sectional study of intima-media thickness, ethnicity, metabolic syndrome, and cardiovascular risk in 2268 study participants. Mayo Clin Proc 2009, 84(3):221-228.

2. Sever P, Dahlof B, Poulter N, Wedel H, Beevers G, Caulfield M, Collins R, Kjeldsen S, Kristinsson A, McInnes G, et al: Potential synergy between lipidlowering and blood-pressure-lowering in the Anglo-Scandinavian Cardiac Outcomes Trial. Eur Heart J 2006, 27(24):2982-2988.

3. Scuteri A, Manolio TA, Marino EK, Arnold AM, Lakatta EG: Prevalence of specific variant carotid geometric patterns and incidence of cardiovascular events in older persons. The Cardiovascular Health Study (CHS E-131). J Am Coll Cardiol 2004, 43(2):187-193.

4. Nichols WW, Pepine CJ, O'Roure MF: Carotid-artery intima and media thickness as a risk factor for myocardial infarction and stroke. $N$ Engl J Med 1999, 340(22):1762-1763.

5. O'Leary DH, Polak JF, Kronmal RA, Manolio TA, Burke GL, Wolfson SK Jr Carotid-artery intima and media thickness as a risk factor for myocardial infarction and stroke in older adults. Cardiovascular Health Study Collaborative Research Group. N Engl J Med 1999, 340(1):14-22.

6. Al-Shali K, House AA, Hanley AJ, Khan HM, Harris SB, Mamakeesick M, Zinman B, Fenster A, Spence JD, Hegele RA: Differences between carotid wall morphological phenotypes measured by ultrasound in one, two and three dimensions. Atherosclerosis 2005, 178(2):319-325.

7. Kitamura A, Iso H, Imano H, Ohira T, Okada T, Sato S, Kiyama M, Tanigawa T, Yamagishi K, Shimamoto T: Carotid intima-media thickness and plaque characteristics as a risk factor for stroke in Japanese elderly men. Stroke 2004, 35(12):2788-2794.

8. Brook RD, Bard RL, Patel S, Rubenfire M, Clarke NS, Kazerooni EA, Wakefield TW, Henke PK, Eagle KA: A negative carotid plaque area test is superior to other noninvasive atherosclerosis studies for reducing the likelihood of having underlying significant coronary artery disease. Arterioscler Thromb Vasc Biol 2006, 26(3):656-662.

9. Prati P, Vanuzzo D, Casaroli M, Bader G, Mos L, Pilotto L, Canciani L, Ruscio M, Touboul PJ: Determinants of carotid plaque occurrence. A long-term prospective population study: the San Daniele Project. Cerebrovasc Dis 2006, 22(5-6):416-422

10. Prabhakaran S, Rundek T, Ramas R, Elkind MS, Paik MC, Boden-Albala B, Sacco RL: Carotid plaque surface irregularity predicts ischemic stroke: the northern Manhattan study. Stroke 2006, 37(11):2696-2701.

11. Rubin MR, Rundek T, McMahon DJ, Lee HS, Sacco RL, Silverberg SJ: Carotid artery plaque thickness is associated with increased serum calcium levels: The Northern Manhattan study. Atherosclerosis 2007, 194(2):426-432.

12. Crouse JR, Bots ML, Evans GW, Palmer MK, O'Leary DH, Grobbee DE, Raichlen JS: Does baseline carotid intima-media thickness modify the effect of rosuvastatin when compared with placebo on carotid intimamedia thickness progression? The METEOR study. Eur J Cardiovasc Prev Rehabil 2010, 17(2):223-229.

13. Bedi US, Singh M, Singh PP, Bhuriya R, Bahekar A, Molnar J, Khosla S, Arora R: Effects of Statins on Progression of Carotid Atherosclerosis as Measured By Carotid Intimal-Medial Thickness: A Meta-Analysis of Randomized Controlled Trials. J Cardiovasc Pharmacol Ther 2010, 15(3):268-273.

14. Vergeer M, Zhou R, Bots ML, Duivenvoorden R, Koglin J, Akdim F, Mitchel YB, Huijgen R, Sapre A, de Groot E, et al: Carotid atherosclerosis progression in familial hypercholesterolemia patients: a pooled analysis of the ASAP, ENHANCE, RADIANCE 1, and CAPTIVATE studies. Circ Cardiovasc Imaging 2010, 3(4):398-404

15. Zanchetti A, Crepaldi G, Bond MG, Gallus G, Veglia F, Mancia G, Ventura A, Baggio G, Sampieri L, Rubba P, et al: Different effects of antihypertensive regimens based on fosinopril or hydrochlorothiazide with or without lipid lowering by pravastatin on progression of asymptomatic carotid atherosclerosis: principal results of PHYLLIS--a randomized double-blind tria. Stroke 2004, 35(12):2807-2812.

16. Zanchetti A, Bond MG, Hennig M, Neiss A, Mancia G, Dal Palu C, Hansson L, Magnani B, Rahn KH, Reid JL, et al: Calcium antagonist lacidipine slows down progression of asymptomatic carotid atherosclerosis: principal results of the European Lacidipine Study on Atherosclerosis (ELSA), a randomized, doubleblind, long-term trial. Circulation 2002, 106(19):2422-2427.

17. Su TC, Chien KL, Jeng JS, Chang CJ, Hsu HC, Chen MF, Sung FC, Lee YT: Pulse pressure, aortic regurgitation and carotid atherosclerosis: a comparison between hypertensives and normotensives. IntJ ClinPract 2006, 60(2):134-140.

18. Chien KL, Sung FC, Hsu HC, Su TC, Lin RS, Lee $Y T$ : Apolipoprotein A1 \& B, and stroke events in a community-based cohort in Taiwan: Report of Chin-Shan Community Cardiovascular Study. Stroke 2002, 33:39-44.

19. Lee YT, Lin RS, Sung FC, Yang CY, Chien KL, Chen WJ, Su TC, Hsu HC, Huang YC: Chin-Shan Community Cardiovascular Cohort in Taiwan: baseline data and five-year follow-up morbidity and mortality. Journal of Clinical Epidemiology 2000, 53:836-846.

20. Chobanian AV, Bakris GL, Black HR, Cushman WC, Green LA, Izzo JL Jr, Jones DW, Materson BJ, Oparil S, Wright JT Jr, et al: The Seventh Report of the Joint National Committee on Prevention, Detection, Evaluation, and Treatment of High Blood Pressure: the JNC 7 report. JAMA 2003, 289(19):2560-2572.

21. Chien KL, Lee YT, Sung FC, Hsu HC, Su TC, Lin RS: Hyperinsulinemia and related atherosclerotic risk factors in the population at cardiovascular risk: a community-based study. Clinical Chemistry 1999, 45(6 Pt 1):838-846.

22. Chien KL, Sung FC, Hsu HC, Su TC, Chang WD, Lee YT: Relative importance of atherosclerotic risk factors for coronary heart disease in Taiwan. EurJ CardiovascPrevRehabil 2005, 12(2):95-101.

23. Wieland H, Seidel D: A simple specific method for precipitation of low density lipoproteins. Journal of Lipid Research 1983, 24:904-909.

24. Su TC, Jeng JS, Chien KL, Sung FC, Hsu HC, Lee YT: Hypertension status is the major determinant of carotid atherosclerosis: A community-based study in Taiwan. Stroke 2001, 32(10):2265-2271.

25. Stein JH, Korcarz CE, Hurst RT, Lonn E, Kendall CB, Mohler ER, Najja SS, Rembold CM, Post WS: Use of carotid ultrasound to identify subclinical vascular disease and evaluate cardiovascular disease risk: a consensus statement from the American Society of Echocardiography Carotid Intima-Media Thickness Task Force. Endorsed by the Society for Vascular Medicine. J Am Soc Echocardiogr 2008, 21(2):93-111. quiz 189-190.

26. Su TC, Jeng JS, Chien KL, Torng PL, Sung FC, Lee YT: Measurement reliability of common carotid artery intima-media thickness by ultrasonographic assessement. J Med Ultrasound 1999, 7:73-79.

27. Belsley DA, Khu E, Welsch RE: Regression diagnostics. New York: Wiley; 1980

28. Tu YK, Jackson M, Kellett M, Clerehugh V: Direct and indirect effects of interdental hygiene in a clinical trial. J Dent Res 2008, 87(11):1037-1042.

29. Tu YK, D'Aiuto F, Baelum V, Gilthorpe MS: An introduction to latent growth curve modelling for longitudinal continuous data in dental research. Eur J Oral Sci 2009, 117(4):343-350.

30. Kline RB: Principles and practice of structural equation modeling. 2nd edition. New York: Guilford Press; 2005.

31. Muthén LK, Muthén BO: Mplus User's Guide. 5th edition. Los Angeles, CA: Muthén \& Muthén; 2007.

32. Koskinen J, Kahonen M, Viikari JS, Taittonen L, Laitinen T, Ronnemaa T, Lehtimaki T, Hutri-Kahonen N, Pietikainen M, Jokinen E, et al: Conventional cardiovascular risk factors and metabolic syndrome in predicting carotid intima-media thickness progression in young adults: the cardiovascular risk in young Finns study. Circulation 2009, 120(3):229-236.

33. Fadini GP, Coracina A, Inchiostro S, Tiengo A, Avogaro A, de Kreutzenberg SV: A stepwise approach to assess the impact of clustering cardiometabolic risk factors on carotid intima-media thickness: the metabolic syndrome no-more-than-additive. Eur J Cardiovasc Prev Rehabil 2008, 15(2):190-196.

34. Kastelein JJ, Akdim F, Stroes ES, Zwinderman AH, Bots ML, Stalenhoef AF, Visseren FL, Sijbrands EJ, Trip MD, Stein EA, et al: Simvastatin with or without ezetimibe in familial hypercholesterolemia. N Engl J Med 2008, 358(14):1431-1443.

35. Crouse JR 3rd, Raichlen JS, Riley WA, Evans GW, Palmer MK, O'Leary DH, Grobbee DE, Bots ML: Jama 2007, 297(12):1344-1353. 
36. Furberg CD, Adams HP Jr, Applegate WB, Byington RP, Espeland MA, Hartwell T, Hunninghake DB, Lefkowitz DS, Probstfield J, Riley WA, et al: Effect of lovastatin on early carotid atherosclerosis and cardiovascular events. Asymptomatic Carotid Artery Progression Study (ACAPS) Research Group. Circulation 1994, 90:679-1687.

37. Salonen R, Nyyssonen K, Porkkala E, Rummukainen J, Belder R, Park JS, Salonen JT: Kuopio Atherosclerosis Prevention Study (KAPS). A population-based primary preventive trial of the effect of LDL lowering on atherosclerotic progression in carotid and femoral arteries. Circulation 1995, 92(7):1758-1764.

38. Byington RP, Furberg CD, Crouse JR 3rd, Espeland MA, Bond MG: Pravastatin, Lipids, and Atherosclerosis in the Carotid Arteries (PLAC-II). Am J Cardiol 1995, 76(9):54C-59C

39. Hedblad B, Wikstrand J, Janzon L, Wedel H, Berglund G: Low-dose metoprolol CR/XL and fluvastatin slow progression of carotid intima-media thickness: Main results from the Beta-Blocker Cholesterol-Lowering Asymptomatic Plaque Study (BCAPS). Circulation 2001, 103(13):1721-1726.

40. Sawayama Y, Shimizu C, Maeda N, Tatsukawa M, Kinukawa N, Koyanagi S, Kashiwagi S, Hayashi J: Effects of probucol and pravastatin on common carotid atherosclerosis in patients with asymptomatic hypercholesterolemia. Fukuoka Atherosclerosis Trial (FAST). J Am Coll Cardiol 2002, 39(4):610-616.

41. de Groot E, Jukema JW, van Swijndregt AD M, Zwinderman AH, Ackerstaff RG, van der Steen AF, Bom N, Lie Kl, Bruschke AV: B-mode ultrasound assessment of pravastatin treatment effect on carotid and femoral artery walls and its correlations with coronary arteriographic findings: a report of the Regression Growth Evaluation Statin Study (REGRESS). J Am Coll Cardiol 1998, 31(7):1561-1567.

42. Tu YK, Baelum V, Gilthorpe MS: A structural equation modelling approach to the analysis of change. Eur J Oral Sci 2008, 116(4):291-296.

43. Curran PJ, Hussong AM: The use of latent trajectory models in psychopathology research. J Abnorm Psychol 2003, 112(4):526-544.

44. McArdle JJ: Latent variable modeling of differences and changes with longitudinal data. Annu Rev Psychol 2009, 60:577-605.

45. Stull DE: Analyzing growth and change: latent variable growth curve modeling with an application to clinical trials. Qual Life Res 2008, 17(1):47-59.

46. Lorenz MW, Markus HS, Bots ML, Rosvall M, Sitzer M: Prediction of clinical cardiovascular events with carotid intima-media thickness: a systematic review and meta-analysis. Circulation 2007, 115(4):459-467.

47. Chien KL, Su TC, Jeng JS, Hsu HC, Chang WT, Chen MF, Lee YT, Hu FB: Carotid artery intima-media thickness, carotid plaque and coronary heart disease and stroke in Chinese. PLOS ONE 2008, 3(10):e3435.

doi:10.1186/1471-2261-12-66

Cite this article as: Chien et al:: Differential effects of the changes of LDL cholesterol and systolic blood pressure on the risk of carotid artery atherosclerosis. BMC Cardiovascular Disorders 2012 12:66.

\section{Submit your next manuscript to BioMed Central and take full advantage of:}

- Convenient online submission

- Thorough peer review

- No space constraints or color figure charges

- Immediate publication on acceptance

- Inclusion in PubMed, CAS, Scopus and Google Scholar

- Research which is freely available for redistribution

Submit your manuscript at www.biomedcentral.com/submit 